\section{Commentary: Pulmonary artery sarcoma - an invitation to the masquerade ball}

\author{
Mahesh S. Sharma, MD
}

During the 16th century Italian Renaissance, masquerade balls were popular occasions, most famously in Venice (eg, Carnevale di Venezia). ${ }^{1}$ Primary pulmonary artery sarcoma (PPAS), first described in 1923 by Mandelstamm, ${ }^{2}$ is a rare and aggressive malignancy arising from the mesenchymal cells of the pulmonary artery. It is often masquerades as pulmonary thromboembolic disease due to similar symptoms and radiologic findings. As a result, treatment is often delayed or misguided. The prognosis is often poor, with the median survival time without surgical resection being as low as 6 weeks. ${ }^{3}$ Diagnostic imaging is often complementary, with no single modality being wholly conclusive or pathognomonic of malignancy. However, enhanced magnetic resonance imaging can be particularly useful with sarcoma typically enhancing with gadolinium compared with thrombus in the pulmonary arteries. Blackmon and colleagues ${ }^{4}$ reported a staging system based on preoperative imaging with general selection criteria predicated on extent of disease and functional status. Due to the paucity of total cases, variance in anatomic involvement and tumor biology, and uncertainty regarding curability, development of meaningful treatment protocols has been challenging. Nevertheless, surgical removal of tumor (R0 resection) remains the mainstay of treatment as part of a multimodality approach for alleviation of symptoms, local control, and the potential to increase long-term survival.

Malik and colleagues ${ }^{5}$ describe a case in which a patient was treated for presumed pulmonary embolism for 6 months

\footnotetext{
From the Department of Surgery, The University of North Carolina at Chapel Hill, Chapel Hill, NC.

Disclosures: The author reported no conflicts of interest.

The Journal policy requires editors and reviewers to disclose conflicts of interest and to decline handling or reviewing manuscripts for which they may have a conflict of interest. The editors and reviewers of this article have no conflicts of interest.

Received for publication Oct 29, 2021; revisions received Oct 29, 2021; accepted for publication Nov 1, 2021; available ahead of print Nov 5, 2021.

Address for reprints: Mahesh S. Sharma, MD, Department of Surgery, The University of North Carolina at Chapel Hill, 3040 Burnett Womack Building, CB 7065, Chapel Hill, NC 27599 (E-mail: mahesh_sharma@med.unc.edu).

JTCVS Techniques 2021;10:315-6

2666-2507

Copyright (C) 2021 The Author(s). Published by Elsevier Inc. on behalf of The American Association for Thoracic Surgery. This is an open access article under the CC BY-NC-ND license (http://creativecommons.org/licenses/by-nc-nd/4.0/).

https://doi.org/10.1016/j.xjtc.2021.11.004
}

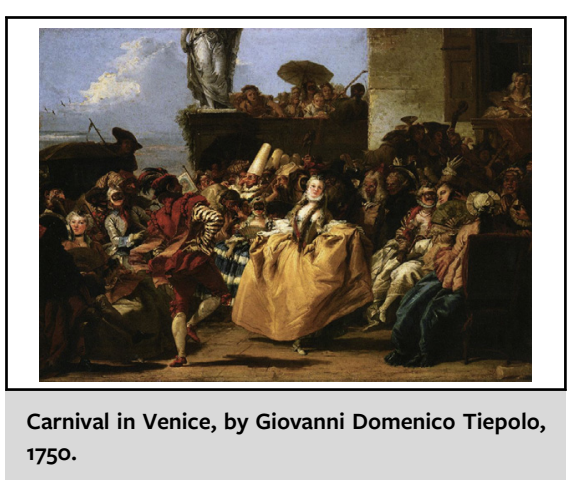

\begin{abstract}
CENTRAL MESSAGE
PPAS is a rare, aggressive malignancy that mimics pulmonary thromboembolic disease. Delayed treatment leads to poor prognosis. Extirpative surgery with adjuvant chemotherapy and radiation is needed.
\end{abstract}

before being referred for surgical evaluation secondary to progression of disease. Due to extensive involvement of the right pulmonary artery to the hilum as well as the main pulmonary trunk to the pulmonary valve with partial involvement of the left pulmonary artery, the authors opted for radical excision, including the pulmonary root with homograft reconstruction and right pneumonectomy. Their video details the technical conduct of the operation. The authors favored radical excision as opposed to endarterectomy with the addition of pneumonectomy in this case. This treatment paradigm is similar to the experience from the group in Houston ${ }^{5}$ who advocate for complete full-thickness resection with reconstruction and selective addition of pneumonectomy for distal pulmonary arterial involvement. More recently, Wyler von Ballmoos and colleages ${ }^{6}$ advocate for a staged approach by which the pneumonectomy is completed at a second operation. This was based on their experience with a combined approach exerting a pronounced physiologic burden, higher transfusion requirements, and the propensity for pulmonary edema in the remaining lung. ${ }^{6}$ Other groups ${ }^{7,8}$ have recommended endarterectomy for PPAS. ${ }^{9}$ We agree that the high risk $(40 \%$ $75 \%$ ) of local recurrence warrants a more definitive oncologic procedure, when technically feasible, because it offers 
the best chance for long-term survival. Additionally, the effects of increased cardiopulmonary bypass time and the circulatory arrest needed for endarterectomy are less desirable. Neoadjuvant chemoradiation allows for the potential assessment of tumor responsiveness and treatment of micrometastatic disease before surgical resection. This warrants further study because this approach to PPAS has the potential to exclude patients for surgical resection based on lack of response to nonstandard chemotherapy regimens.

\section{References}

1. Sethre J. The Souls of Venice. McFarland Publishing; 2003. 132.

2. Mandelstamm M. Uber primare Neubildungen des Herzens. Virchows Arch (Pathol Anat). 1923;245:43-57.
3. Barmpas A, Giannakidis D, Fyntanidou V, Koulouris C, Mantalobas S, Pavlidis E, et al. Intimal sarcoma of the pulmonary artery, a diagnostic enigma. AME Case Rep. 2019;3:32.

4. Blackmon SH, Rice DC, Correa AM, Mehran R, Putnam JB, Smythe WR, et al. Management of primary pulmonary artery sarcomas. Ann Thorac Surg. 2009; 87:977-84.

5. Malik MI, Rabbani M, Hage F, Inculet R, Chu MWA. Missed pulmonary artery sarcoma requiring radical excision and pneumonectomy. J Thorac Cardiovasc Surg Tech. 2021;10:309-12.

6. Wyler von Ballmoos MC, Chan EY, Reardon MJ. Imaging and surgical treatment of primary pulmonary artery sarcoma. Int J Cardiovasc Imaging. 2019;35:1429-33.

7. Chan EY, Reul RM, Kim MP, Reardon MJ. The "Texas Two-Step" procedure. $J$ Thorac Cardiovasc Surg. 2018;155:285-7.

8. Yin K, Zhang Z, Luo R, Ji Y, Zheng D, Lin Y, et al. Clinical features and surgical outcomes of pulmonary artery sarcoma. J Thorac Cardiovasc Surg. 2018;155: 1109-15.e1.

9. Han Y, Zhen Y, Liu X, Zheng X, Zhang J, Zhai Z, et al. Surgical treatment of primary pulmonary artery sarcoma. Gen Thorac Cardiovasc Surg. 2021;69:638-45. https://doi.org/10.1007/s11748-020-01476-2 